\title{
Carrera 50: Arquitectura, cultura y tradición
}

\section{Race 50: Architecture, culture and tradition}

\author{
DOI: 10.17981/mod.arq.cuc.24.1.2020.07
}

Artículo. Fecha de Recepción: 28/02/2020. Fecha de Aceptación: 07/04/2020.

\section{Paola Ivama Hernández A}

Universidad de la Costa. Barranquilla (Colombia)

\author{
phernande3@cuc.edu.co
}

\section{Andrés Rueda Pineda}

Universidad de la Costa. Barranquilla (Colombia)

lrueda14@cuc.edu.co

Para citar este artículo:

Hernández, P. y Rueda, A. (2020). Carrera 50: Arquitectura, cultura y tradición. MODULO ARQUITECTURA CUC, no. 24, pp. 117-156, 2020. DOI: http://doi.org/10.17981/mod.arq.cuc.24.1.2020.07

\section{Resumen}

La carrera 50, en el ámbito de movilidad vehicular, es un eje vial importante en la ciudad de Barranquilla. Por tanto, el Distrito decidió emprender un proyecto para la transformación de esta carrera, construyendo un par vial, que permitiera mejorar la movilidad vehicular en la ciudad de norte a sur y viceversa, así como el mejoramiento y disponibilidad de espacio público adecuado. Durante el año 2015 y 2016, se realizaron una serie de fotografías en las cuales se buscó captar las edificaciones que se encontraban en Barrio Abajo y que iban a ser derrumbadas para dar comienzo al Par Vial de la carrera 50. El objetivo de este artículo es realizar un recuento del valor arquitectónico, histórico, cultural y urbano que tiene y que ha tenido la carrera 50 a lo largo de estas décadas, presentando una breve reseña histórica de Barrio Abajo y la carrera 50, presentando una serie de fotografías que reflejan las edificaciones y/o viviendas antiguas demolidas en la construcción del proyecto del par vial y la transformación de la carrera 50 en un nuevo eje de movilidad vehicular y un nodo cultural para la ciudad de Barranquilla.

Palabras claves: Carrera 50; par vial; valor arquitectónico e histórico; cultura

\section{Abstract}

The avenue 50, in the field of vehicular mobility, is an important road axis in the city of Barranquilla. Therefore, the District decided to undertake a project for the transformation of this race, building a road pair, which would allow to improve vehicular mobility in the city from north to south and vice versa, as well as the improvement and availability of adequate public space. During the year 2015 and 2016, a series of photographs were taken in which it was sought to capture the buildings that were in Barrio Abajo and that were going to be collapsed to start the Road Par of avenue 50. The objective of this article is Make a count of the architectural, historical, cultural and urban value that it has and that has had the avenue 50 over these decades, presenting a brief historical overview of Barrio Abajo and the avenue 50 , presenting a series of photographs that reflect the buildings and / or old houses demolished in the construction of the road pair project and the transformation of the avenue 50 into a new axis of vehicular mobility and a cultural node for the city of Barranquilla.

Keywords: Avenue 50; road pair; architectural and historical valueV culture 
La 50 ANTES DEL BAILE

La carrera 50 y Barrio Abajo, tienen un "lazo" cultural, arquitectónico e histórico que se formó hace décadas. Si hay un barrio en la ciudad conectado con su historia y que se podría relacionar con el carácter mismo que identifica al barranquillero, es el Barrio Abajo, considerado por historiadores, intelectuales y académicos, como uno de los más antiguos de la ciudad (Polo, 2014). Es un barrio que nació con el desarrollo de la ciudad, gracias a sus cercaní al río y los diferentes equipamientos como la estación férrea y la Aduana, los cuales permitieron la entrada de la diversidad cultural por parte de las diferentes poblaciones migratorias de oriente y occidente que vinieron asentarse en la ciudad en busca de nuevas oportunidades obligados por los diferentes acontecimientos

Figura 1. Vivienda localizada en la carrera 50 antes de intervenida: Desalojada para demole Fuente: Andrés Rueda Pineda de carácter histórico que se estaban viviendo en ese entonces como las secuelas de destrucción que dejo las guerras mundiales y civiles. La llegada de extranjeros de todas partes del mundo, más los criollos, convirtió al barrio en una mezcla cultural y social que le dio una identidad propia al sector, que luego se vio representada en estilos de vidas, de aquí de la mezcla de costumbres, tuvo origen el carnaval de Barranquilla (Vivas, 2013).

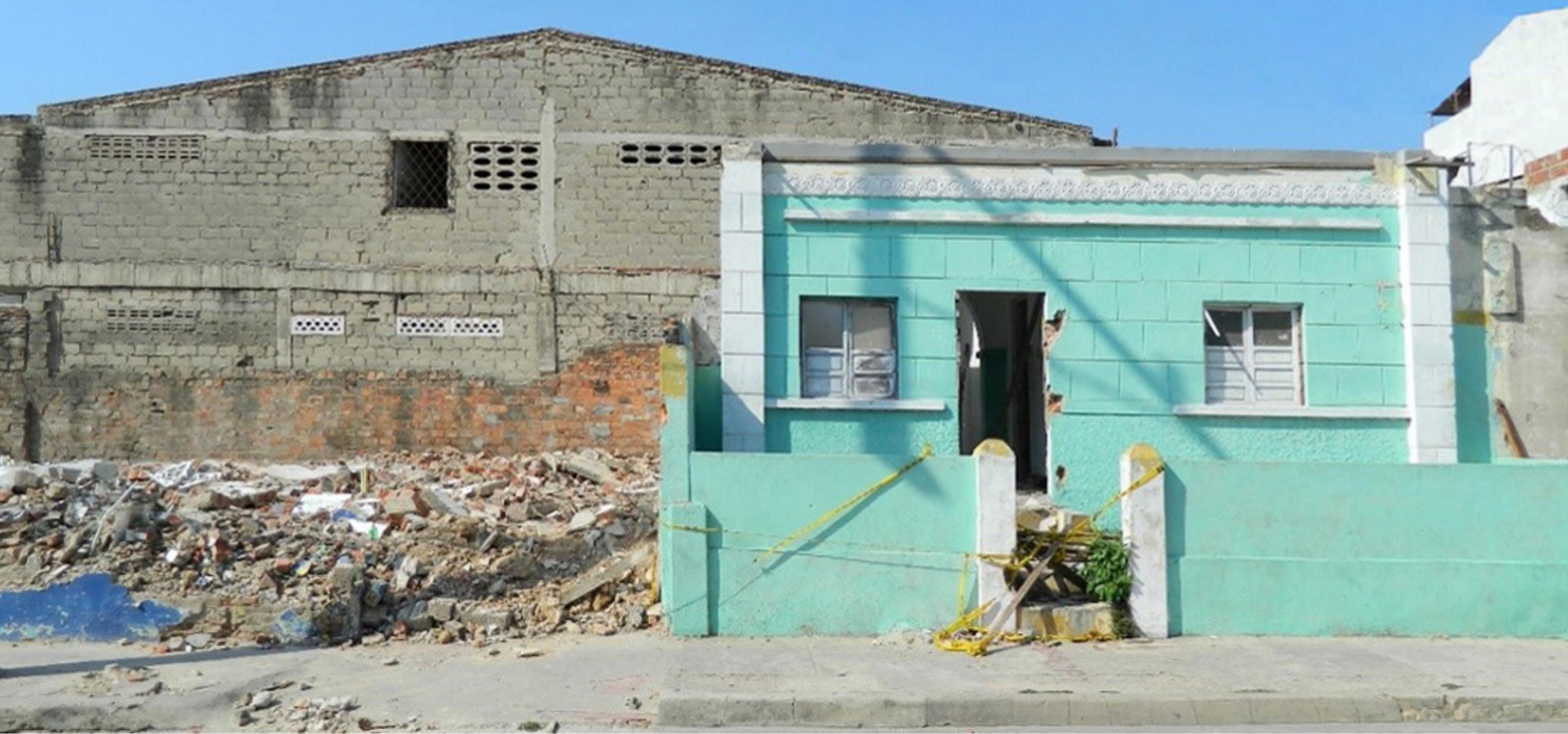


En este sector es donde se hallan los más remotos rastros de la vida barranquillera. Aquí tuvo lugar el auge comercial e industrial que trajeron consigo la vía férrea y el tráfico por el río que le da una importancia política a esta ciudad donde se estableció la primera comunidad proletaria en Colombia (Polo, 2014). Como se mencionó anteriormente el origen y la historia del barrio esta trascendentalmente ligada a las actividades generadas por el comercio, la pequeña y mediana industria, el transporte como medio de apoyo, la navegación fluvial, la industria de la construcción, los servicios navieros, los talleres del Ferrocarril y de la Estación Montoya. Por

Figura 2. Viviendas localizadas en la carrera 50 antes de ser intervenida: Viviendas con antiguas tejas de

cemento, puertas y ventanas de mader Fuente: Andrés Rueda Pineda lo cual el barrio no tuvo una fundación, sino que simplemente se originó debido a un proceso demográfico espontaneo, por cuestiones geograficas y a la necesidad de trabajo de los habitantes de otras ciudades y pueblos de la costa que veían en este territorio el lugar perfecto para

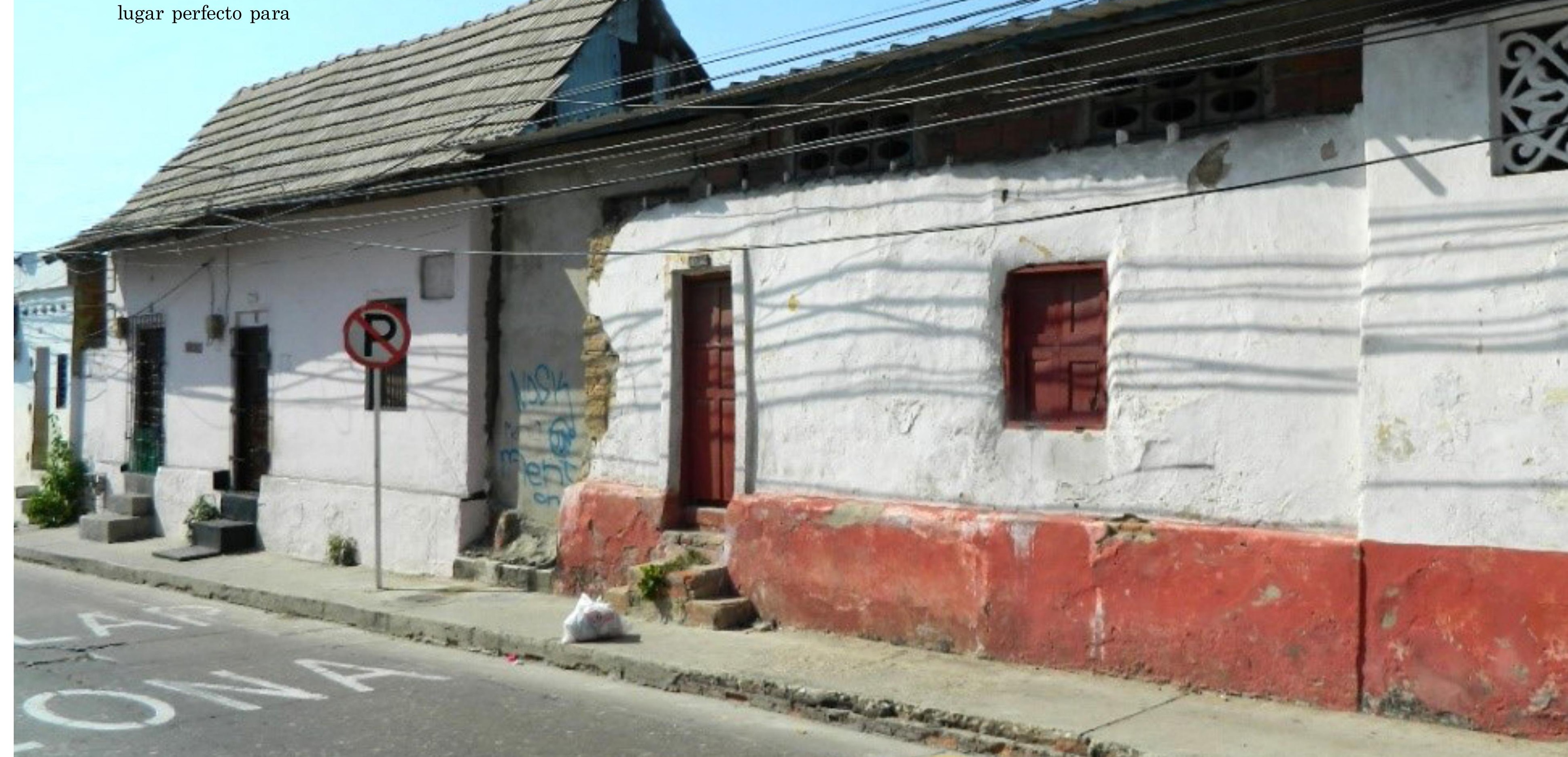

encontrar oportunidades de empleo, ofrecidas por las empresas y talleres que estaban al servicio de navegación fluvial y el transporte 
En el año de 1940, el auge industrial y comercial que le brindaba la seguridad de desarrollo al barrio Abajo empieza a desvanecerse debido a que la línea férrea que comunicaba a Barranquilla con Puerto Colombia se clausuraba, ya que habían logrado comunicar al rio y al mar de manera directa permitiendo la $\mathrm{y}$ al mar todos los productos directamente a la ciudad

(Vivas, 2013). Las majestuoses edificaciones

de la Aduana y la Estación Montoya quedoran

como un recuerdo de lo que venía predestinaran

para el barrio y no fue.

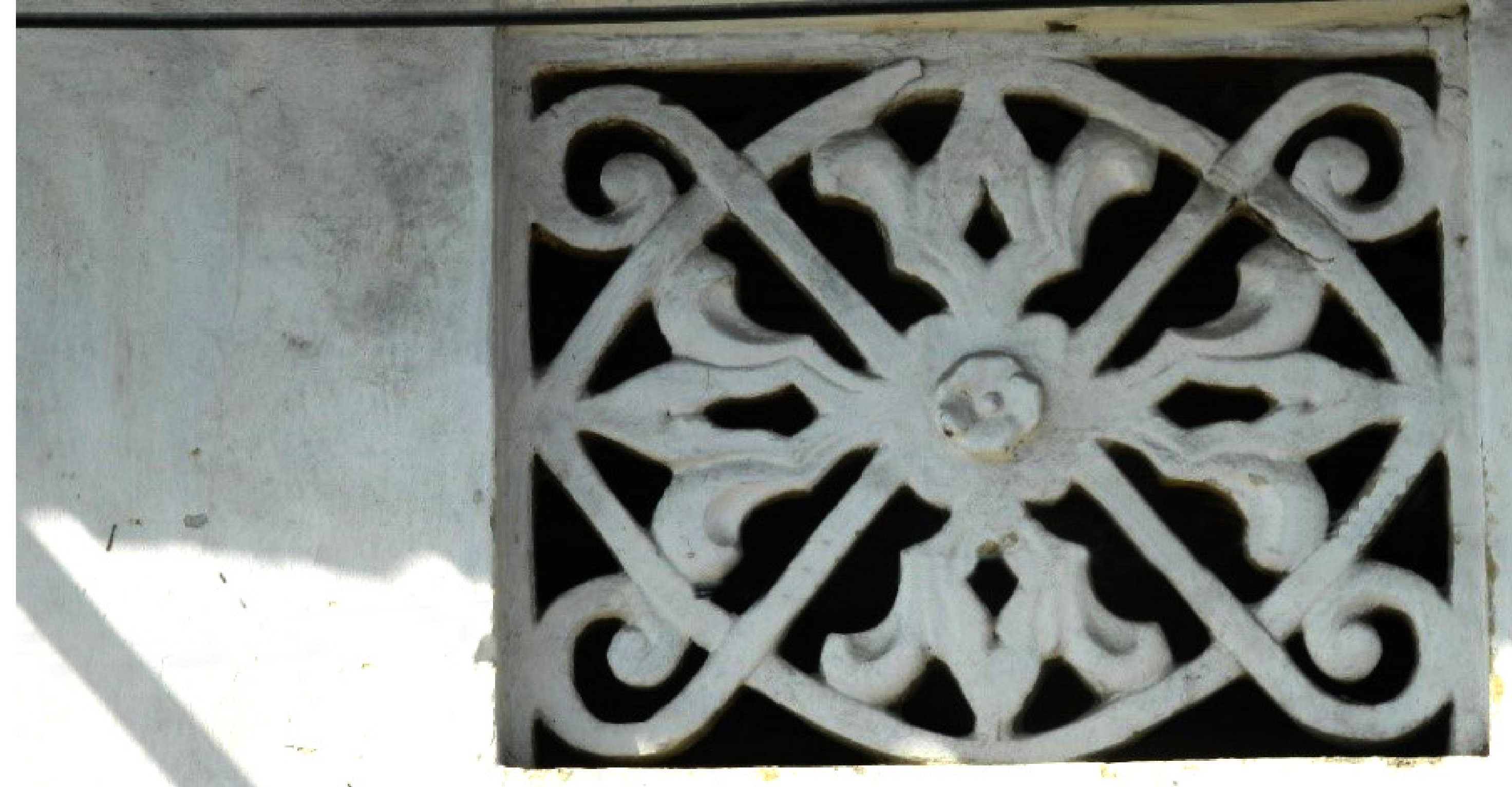

Figura 3. Elemento decorativo como ventana elaborado con cemento.

Fuente: Andrés Rueda Pineda 
En el barrio, así como el tramo de la carrera 50 en el sector, se encuentran y se encontraban viviendas de pesar de que la najor se con a pesmente con techicas constructivas tradicio

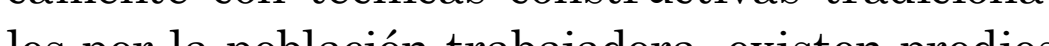
les por la población trabajadlora, existen predios que resaltan por su estilo arquitectónico, valores

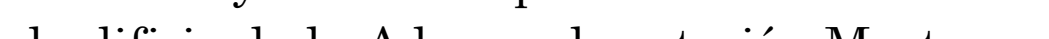
el edificio de la Aduana, la estación Montoya y la casa del carnaval entre otros. Las antiguas casas de bahareque y techos de paja que han sufrido no pocas transformaciones, sumadas a las patrimoniales viviendas con diseño republicano se mezclan con las nuevas fachadas modernas y las convierten en una pieza única y sin parangón en la ciudad (Polo, 2014) Para la realización del proyecto denominado Par vial carrera 50, fue necesario la demolición de alrededor 10 inmuebles pertenecientes al sector patrimonial Barrio Aba $j 0^{1}$, localizados sobre el eje vial de la carrera 50.

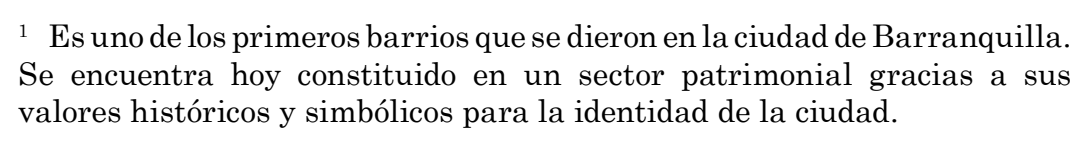

Para el desarrollo de la nueva obra, se intervino un total de 10 inmuebles, catalogados por el Ministerio de Cultura (Resolución No. 3779, 2014), como "Edificios con características tipologicas tradicionales alteradas", por lo que admiten modificación y demolición, según la empresa de transporte masivo (Polo, 2014).

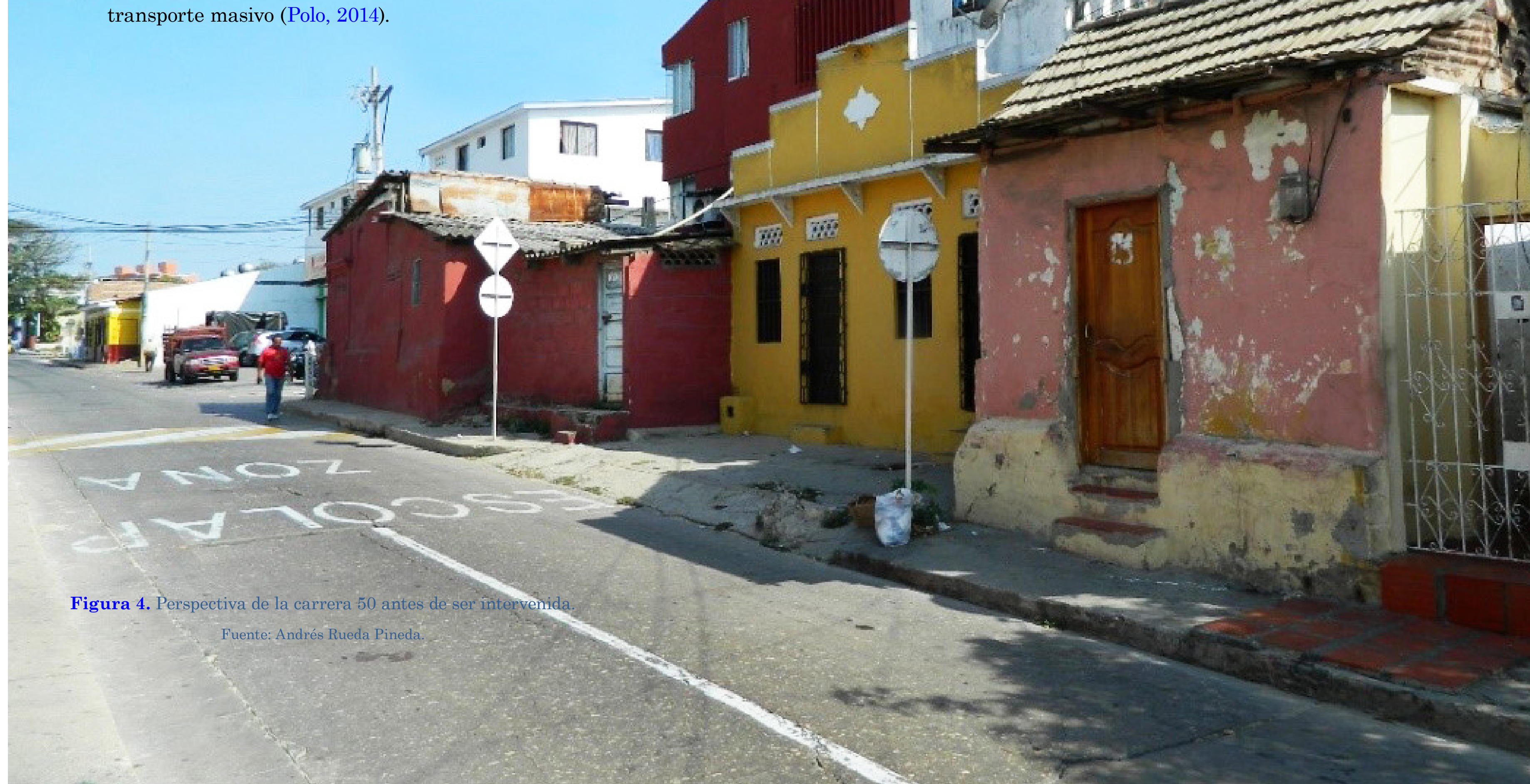


Durante el año 2015 y 2016, se realizaron una serie de fotografías en las cuales se buscó captar as edificaciones que se encontraban en Barrio Abajo y que iban a ser derrumbadas para dar comienzo al Par Vial de la carrera 50. Para ese momento, la ampliación habla empezado, específia Aduan dificaciones el in edifictador, en la antige plaza de la alvana. En mi trayectoria, ventanas, aunque sus fachadas estaban en pie.

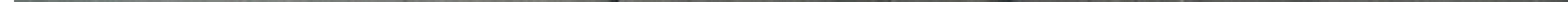


El objetivo fue realizar un registro fotográfico de la cotidianidad de esta zona de la carrera 50 antes de su intervención, mostrando la variedad de estilos arquitectónicos de las edificaciones que iban a demoler. En el sector identifican estilos arquitectónicos coctor e identific que ibs a der

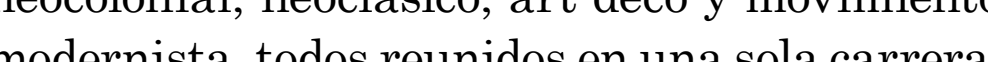
Tste sector de la cam 50 simblizar viaje a pardo, casis pintadas con ciertas viaje a par do la carto verde, has fach - baldosa hidráulicas etc (Figura 1, Figura 2, Figura 3, Figura 4, Figura 5 y Figura 6)

Figura 6. Viviendas localizadas en la carrera 50 antes de ser intervenida: Los colores pasteles hacían parte de
las tonalidades usadas en las fachadas de las viviendas. Fuente: Andrés Rueda Pineda
Muchas de estas viviendas mantenían el mismo estilo e incluso estado desde su construcción, algunas mostraban el deterioro de los años. Eso era lo característico de la carrera 50 antes de ser intervenida, viviendas del recuerdo, calles angostas de doble sentido $\mathrm{y}$ buen ambiente social.

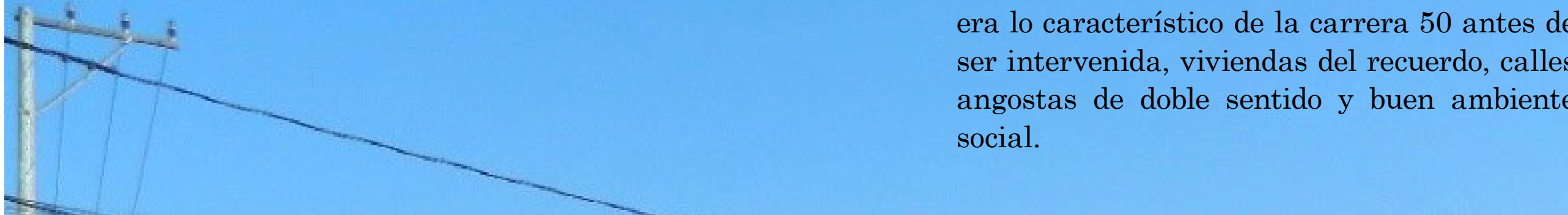

tis

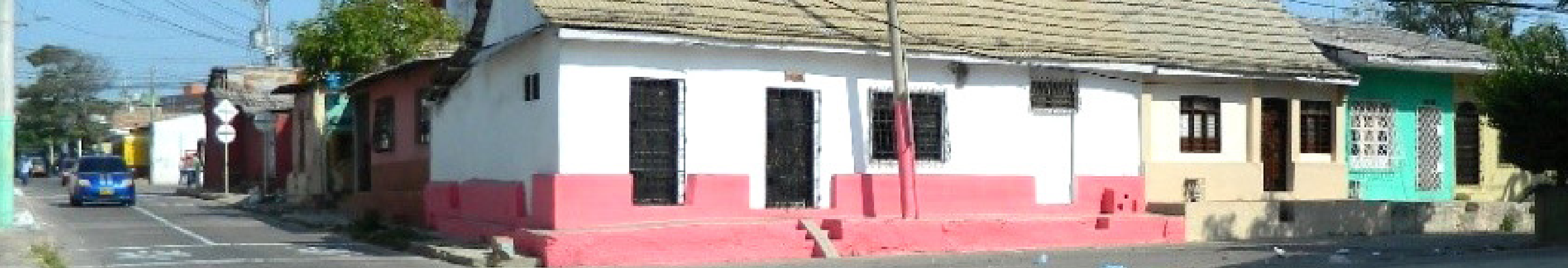
त 
Tiendas de barrio que, normalmente, se localizaban en las esquinas sobre la carrera 50 , con puertas y ventanas de madera con barrotes de hierro, como símbolo de seguridad, logos y avi sos publicitarios de las marcas de productos que vendian, la radio sonando y las personas que llegaban a comprar y aprovechaban para conversar casas antiguas que funcionaban como viviendas y restaurantes y en cada mediodía acogían a de cenas de personas que llegaban por la "corriente" o a comprar sopa; pisos altos con escalones que permitian entrar a las viviendas y para evitar que las aguas de los arroyos entraran al interior de la vivienda; una calle con pavimento en regula estado, andén elevado hasta 30 centímetros del suelo y seguidamente la línea de construcción de las viviendas en su mayoría adosadas unas a otras, que definían este sector con un tejido compacto, suelo no permeable y edificaciones hasta niveles. Esas características sociales y urbanas se identificaban en la carrera 50 antes de ser intervenida, un sector que contaba historia, anécdotas y peripecias (Figura 7, Figura 8 y Figura 9).

Figura 7. La tienda del barrio Fuente: Andrés Rueda Pineda

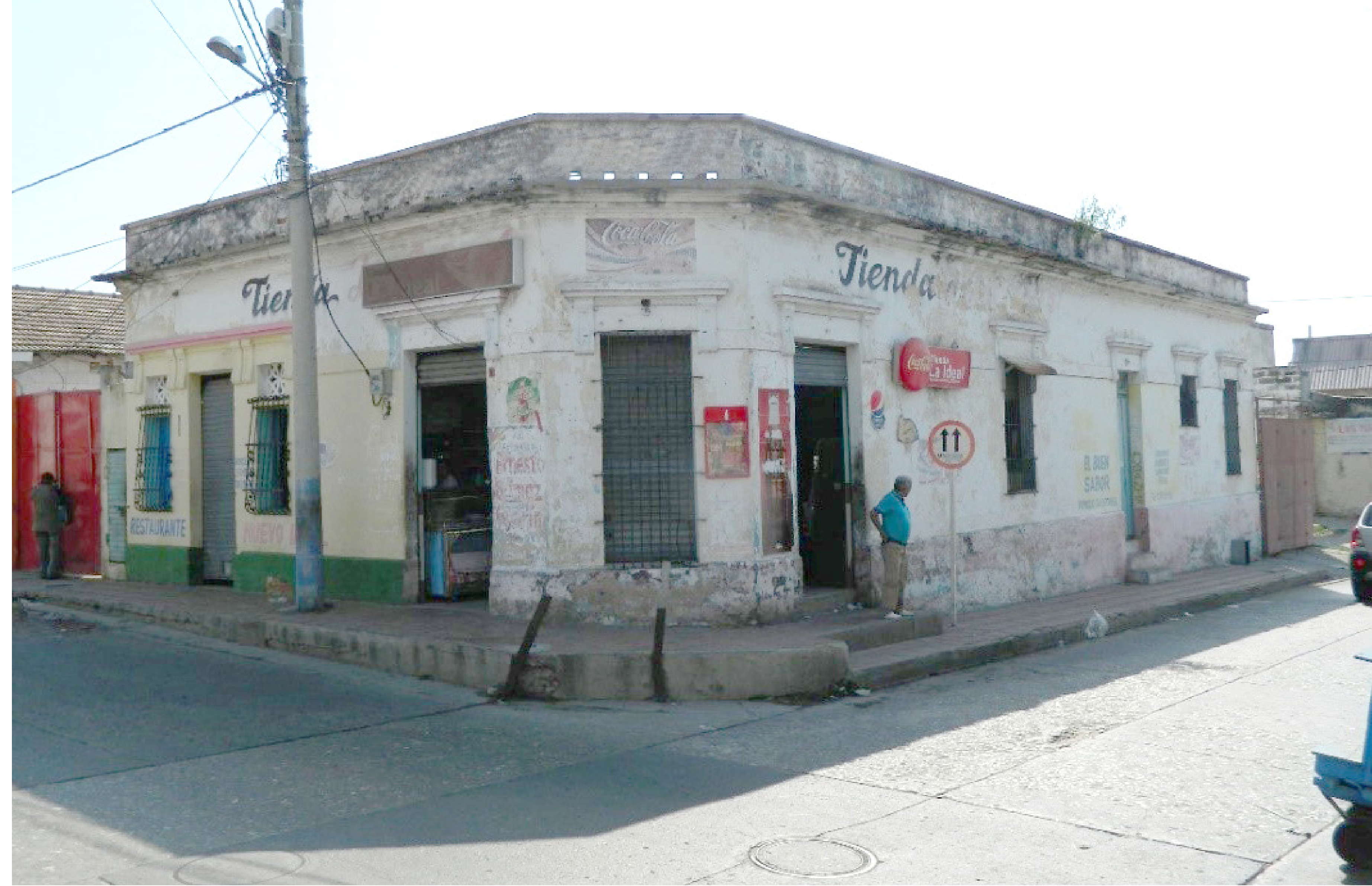




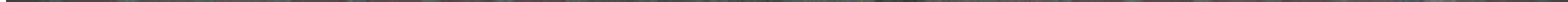


En las visitas realizadas en el sector, uno de

los inquilinos de las viviendas manifestó que no era muy bueno el proyecto de la ampliación de la carrera 50 daba prioridad al avance de la infraes-

tructura vial de la ciudad y en cuanto a la demo-

lición de la vivienda era necesario que se hiciera

porque las vas na "viejas". Una aprecia-

porque subjetiva de la estética de las viviena aprecia-

ción subjetiva de le vista arquitectónica e histónie,

desde el purto de vista ara de lastónica e histórica,

as vivieno (Figura 10, Figura 11, Figura 12 Barrio

Ab. Figura 14, Figura 15, Figura 16, Figura 17

13, Figura 14, Figura 15, Figura 16, Figura 17 y
Figura 18). 


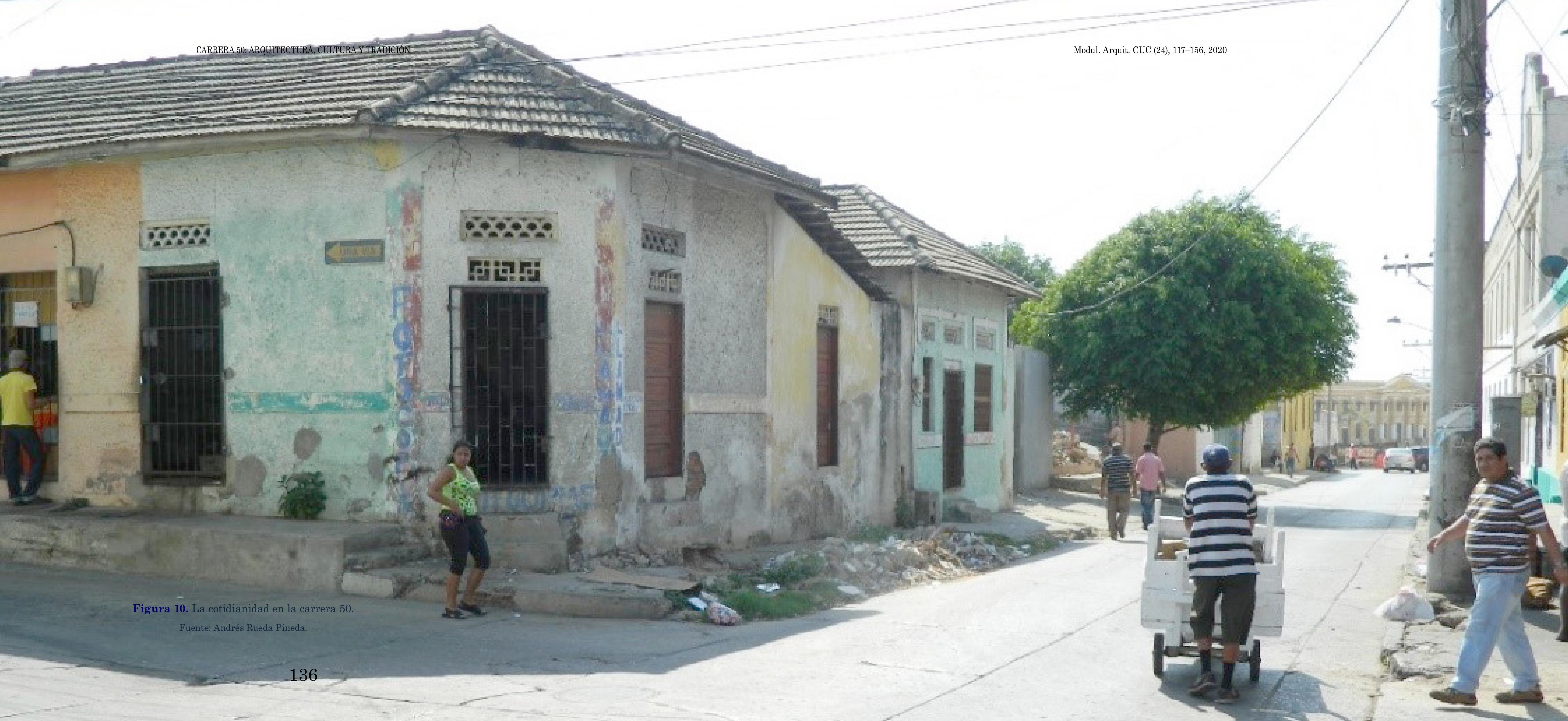


Durante el año 2019, el colectivo "Todomono" realizó el festival "NoConocíElPalma", donde los temas principales se centraron en propuestas para la conservación de la memoria historia de la ciudad y de cien propuestas, fue aceptada para ser parte del evento "la 50 antes del baile", recopilando las memorias del pasado de la carrera 50 , donde actualmente se realiza el evento del carnaval de Barranquilla llamado "Baila la calle". De esta forma, se pensó que si ahora todos conocen la carrera 50 por sus fiestas y no por el valor arquitectonico que tenían las edificaciones que fueron demolidas antes del baila la calle; de una forma sencilla, pero muy llamativa, se nombra el proyecto como "La 50 antes del baile", presentando a partir de una serie de fotografías la riqueza patrimonial que se encontraba en esta y que hoy no nos acompana para poder darle paso al tan anhelado progreso que se viene realizando en la ciudad.

Figura 11. Viviendas de dos niveles localizadas en la carrera Fuente: Andrés Rueda Pineda.

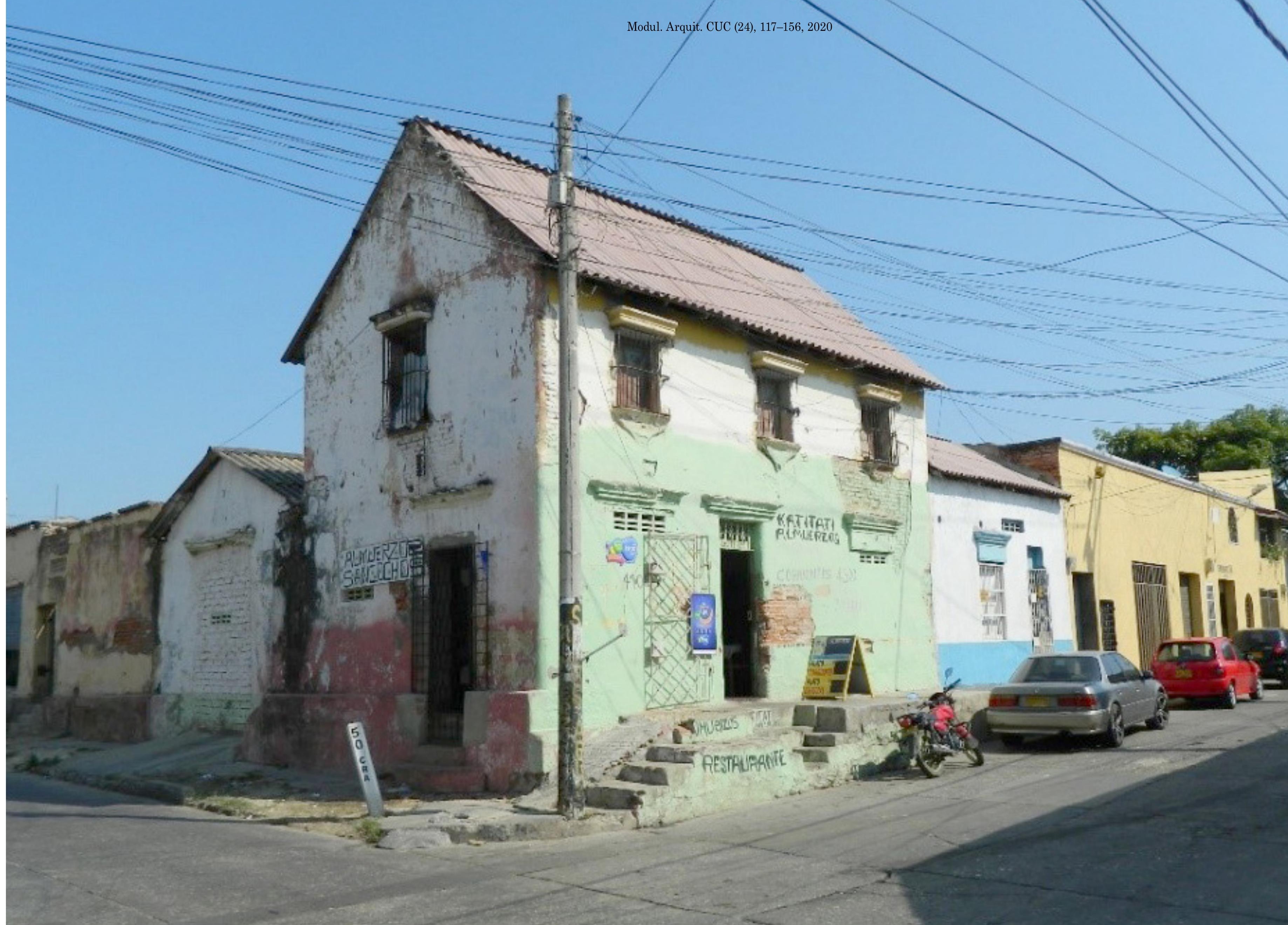


Barrio Abajo, según comentan sus propios haBitantes, no solo ha sido carnaval, comparsas o bailes, también se caracteriza por su gastronomía y tradición popular, donde edificaciones tenían un gran valor arquitectónico e histórico que contribuían a la historia de la ciudad. Así, el recuento fotográfico de la carrera 50 antes del baile, demuestra la importancia y el valor que fue puesto en el olvido de una de las avenidas más importan-

te, actualmente, en la ciudad de Barranquilla. La

carrera 50, en el sector de Barrio Abajo, fue, es

y siempre será un eje de cultura, arquitectura y

tradición de la ciudad. Es importante, reconocer

ese valor arquitectónico de las edificaciones demo-

lidas en la primera etapa de la transformación de

la carrera 50.

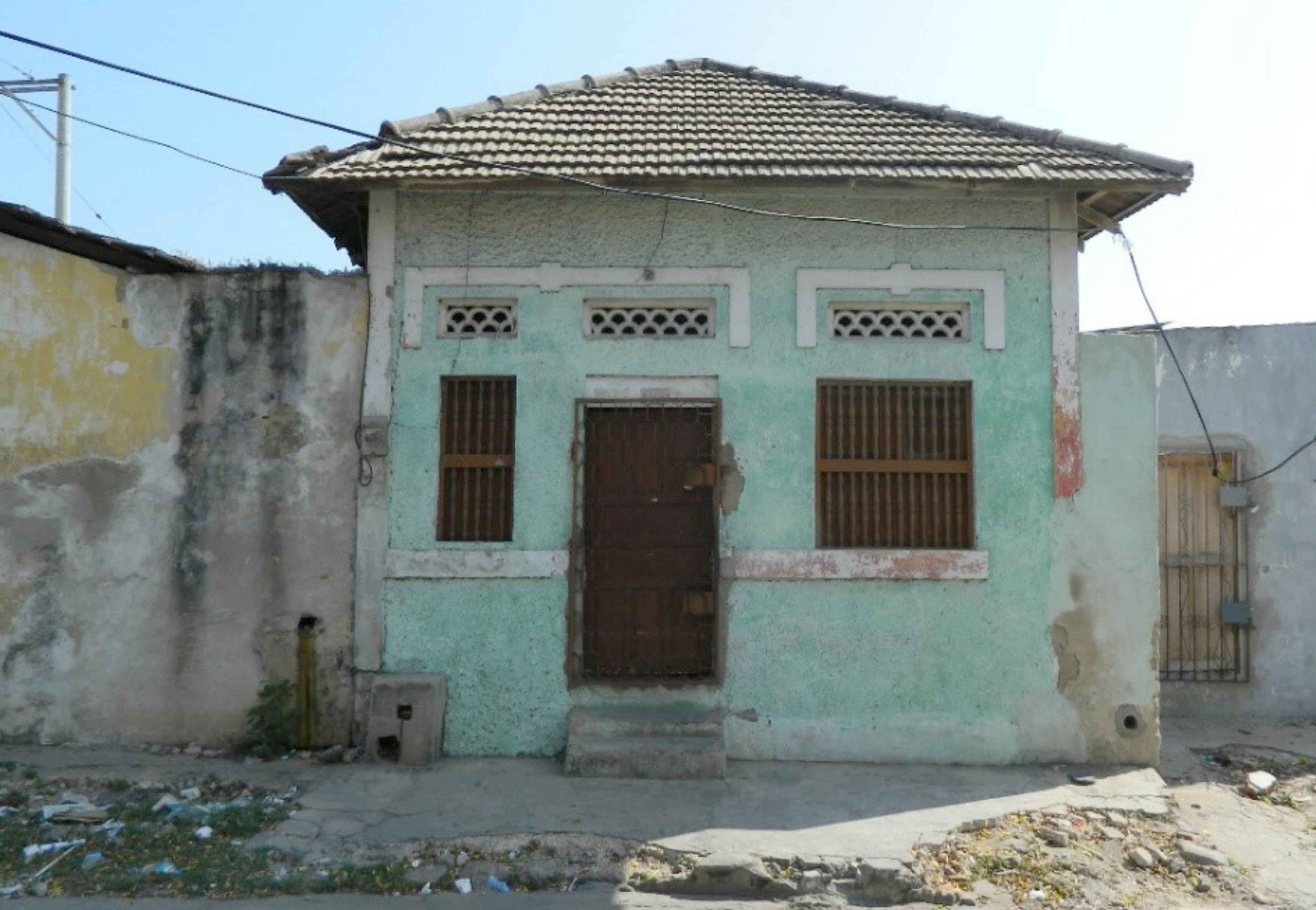




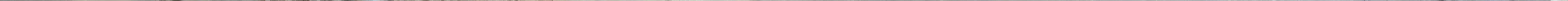




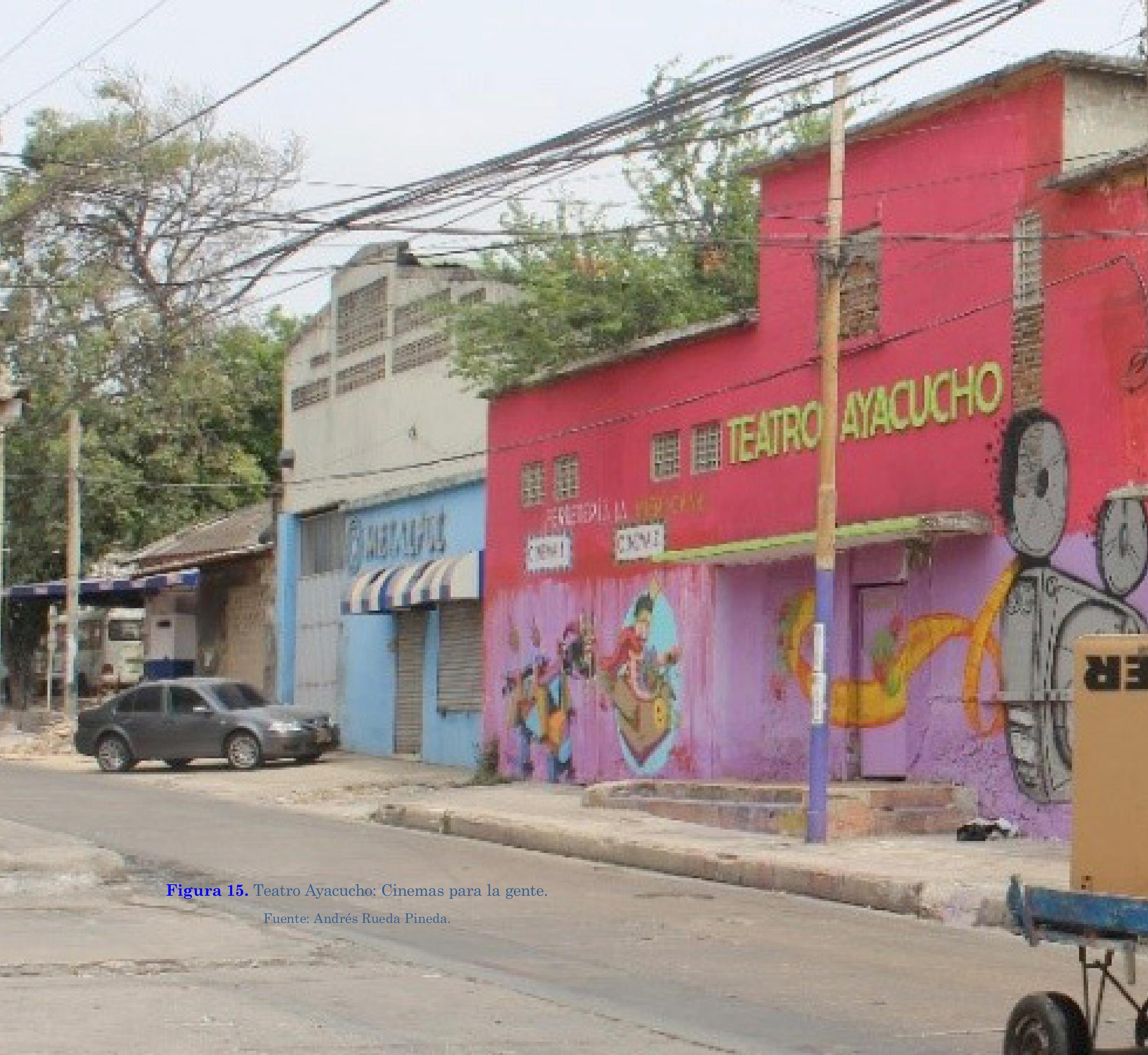


La carrera 50, en el ámbito de movilidad vehicular, es un eje vial importante en la ciudad de Barranquilla. Por tanto, el Distrito decidió emprender un proyecto para la transformación de esta carrera, construyendo un par vial, que permitiera mejorar la movilidad vehicular en a ciudad de norte a sur y viceversa. El proyecto de transformación de la carrera 50 , se llevo a cabo de occidente a oriente desde la calle 88 con carrera 47 hasta la Via 40 y en poco tiempo hasta la misma isla La Loma, y desde la Vía 40 a través de la carrera 50 hasta la calle 91 (EDUBAR, 2018).

En cuanto a la importancia en movilidad vehicular de esta vía, la carrera 50 según la cartografía del sistema de jerarquía vial del Plan de Ordenamiento Territorial de BarranquillaPOT (2012), se define como una vía tipo regional y ante el "Anexo No 6: Perfiles del sistema de movilidad" se clasifica como una vía V3.

Figura 16. Viviendas antiguas en la carrera 50 :
Vestigios del pasado, valor en el presente. Fuente: Andrés Rueda Pineda 
La propuesta del sistema de movilidad implica la aplicación de unos perfilos viales estandarizados y que deben ser aptos para soportar una capacidad vehicular y peatonal de acuerdo a la función que se le asigne dentro del sistema" (Alcaldia de Barranquilla, 2012). La clasificación del tipo de perfil vial sucede como una respuesta a los requerimientos mínimos que exige una vía según su flujo vehicular y peatonal, estos requerimientos se traducen en componente o franjas que se encuentran definidas por el Código de tránsito nacional (Ley 769, 2002).

"De acuerdo al tipo de perfil, este contiene una serie de componentes que lo diferencia y jerarquiza dentro las tipologías propuestas" (Alcaldia de Barranquilla, 2012). En el Distrito existen diferentes tipos de vías clasificadas seexisten diferentes tipos de vias clasificadas según su jerarquia vial la cual es definida según su configuraín dentro de la malla vial de la ciudad, existen vias que solo tienen influencia dentro de la ciudad constituidas como arterias, semi-arterias, colectoras y peatonales, mientras

otras vias crean conexiones entre la ciudad y
sus diferentes municipios aledaños, estas vías

Figura 17. Elementos decorativos
elaborados en cemento que adornaban ciertos andenes en la carrera 50 Fuente: Andrés Rueda Pined se definen como vías regionales. Cabe resaltar que, anteriormente la carrera 50 se constituía con una jerarquia vial tipo colectora, sin embargo, con la actualización del POT se establece como se dice al inicio una vía regional debido al empalme vial que ocurre en la calle 75 con la carrera 51B conocida coloquialmente como "la carretera vieja" para así constituirse como una vía regional.

La carrera 50 pertenece a uno de los principales vía-canales de la ciudad, ya que, por debajo pasan las diferentes redes de infraestructura pública. La transformación de la carrera 50, se trata de una obra que tiene un espacio público, los andenes, un espacio para las personas con movilidad reducida, también se encuentra un banco de ductos con el fin de esconder todos esos cables en las calles para que no estor esos cables en las calles para que no estorben, proyalización del arroyo (Pérez, 2018). Este proyecto es concebido bajo los nuevos elemenrritorial de la ciudad, el cual busca crear una estructura bajo su malla vial que cree una mayor con tividad entre las diferentes zona de la ciudad Una nueva estructura vial, en donde la ciuda se transforma y se onde de grande ejes que van a date una logica distinta a la organizcion de las activides en tinta a la ejganizción a las actividuces en el proctos y en donctivos y por tanto de aplicaprocesos tranfor diva y por tanto de aplicabilidad de nasos tratamientos y normas para finición de los límites de las pieza" (Aledede Barranquilla, 2012). 


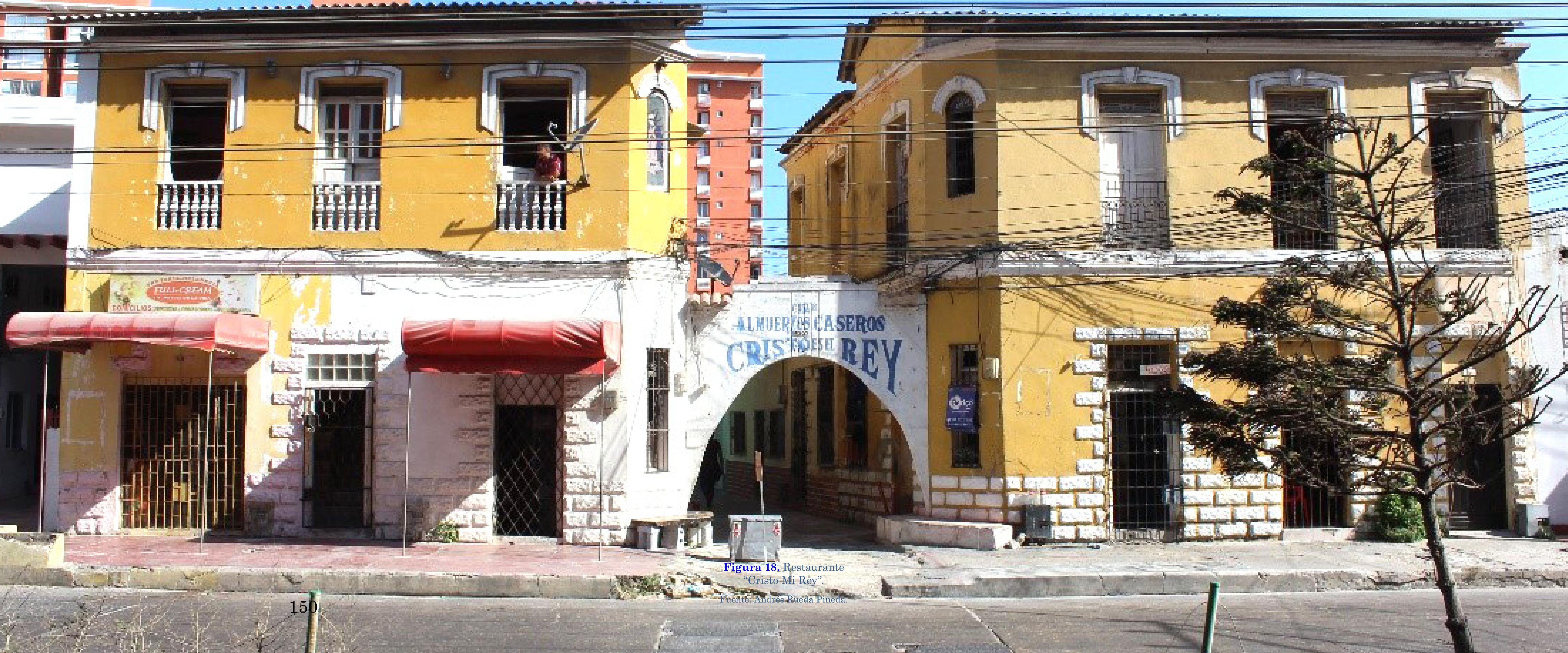


La inversión global en el Par Vial ascendió a unos 58 mil millones de pesos, incluyendo obras civiles, interventoria, adquisición predial y pagos de reconocimientos económicos. EDUBAR tuvo a su cargo las labores de interventoría (EDUBAR, 2018). El proyecto del par vial de la carrera 50, se llevó a cabo por medio de dos etapas de intervención, tal como se definen a continuación (Figura 18):

1. La primera etapa de la construcción se dividió en tres fases: la primera fue desde Barlovento hasta la calle 36 ; la segunda entre las calles 36 y 39 , y la tercera de la calle 39 a la 45 , donde finaliza esta parte del proyecto. La obra fue ejecutada por la Unión Temporal Par Vial Barranquilla, que se ganó la licitación a jar construido el primer tramo se destinaron 12000 millones de pesos. Los recursos se gestionaron a través de un convenio entre la Nación, que aportó el $70 \%$, y el Distrito, con el $30 \%$. 2. Por su parte, la segunda etapa del proyecto, va
desde la Murillo hasta la calle 55 . Este primer tramo se desarrolla entre las calles 45 y $47 \mathrm{y}$ segundo y tercer tramo que van de la calle 48 a la 53 y de la 53 a la 55 . La construcción de esta se800 metros lineales (Guerrero, 2016).

Esta transformación de la carrera 50, constituyó uno de los caminos en la consolidación de la idea de una Barranquilla que vuelve al río. Una ciudad abierta al Rio, con interven tantes en la estructura urbana de este significativo y potencial sector urbano se pretende impulsa su transformación e integración estratégica con la ciudad, lo que requerirá de un manejo especial que direccione su potencialidad y por ende también amerita su redefinición con base a las Piezas (Alcaldia de Barranquilla, 2012). La carrera 50 crea la unión entre el sector de La Loma ${ }^{2}$ y la ciudad a través del puente basculante el cual ya se encuentra construido que permitirá el tráfico marítimo por el río magdalena obedeciendo de nuevo a las nuevas políticas de ordenamiento.

El plan vial de la carrera 50 es la conexión de la ciudad con los diferentes proyectos de desarrollos. La transformación urbanística de Barranquilla en ese sector incluye la prolongación de la Carrera 50, la integración con la Intendencia Fluvial, y la regeneración de Barlovento en este extremo, esto quiere decir que la carrera 50 , es un elemento conector con los diferentes puntos de desarrollo, en este caso, con los proyectos propuestos y así constituir un tejido urbano para la acupuntura de la ciudad. Sin embargo, este pasaje vial no solo es solo un canal de conexión urbano también se constituye como un recorrido cultural entre se diferentes sectores patrimoniales que los conpo(a)

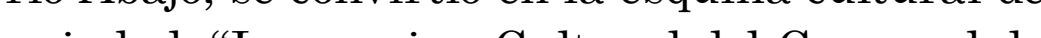
la ciudad: La esquina Cultural del Carnaval de

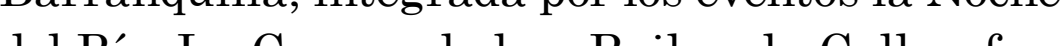
del Rio, La Carnalada yaila a la Calle, ofre" (Ca la cind de Barrongulla, 2018).

2 La Lomaes un terreno ubicado de las orillas del rí Magdalena y se define
como uno de los mayores polos de desarrollos de la ciudad de Barranquilla.

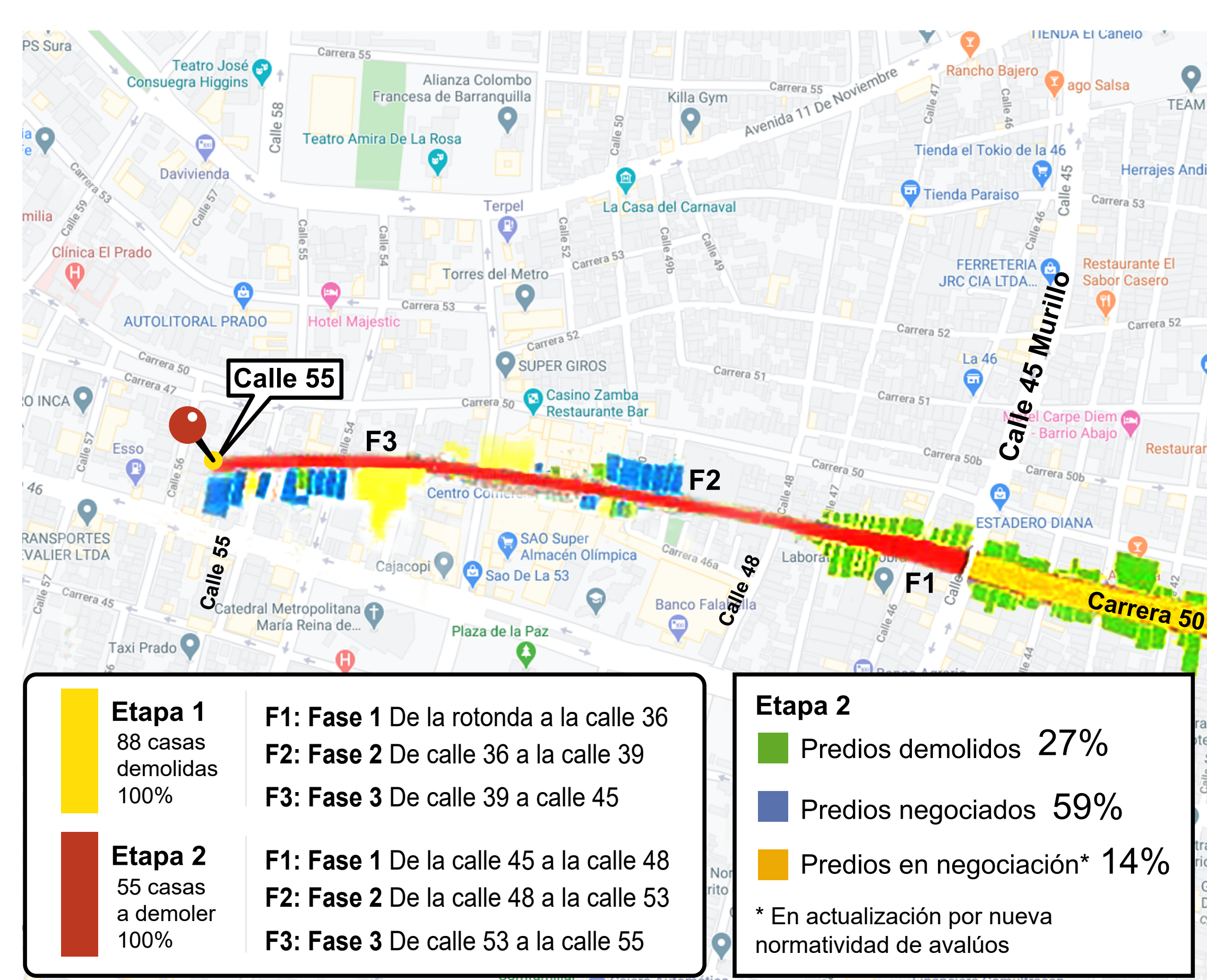

normatividad de avor nueva

Figura 19. Áreas intervenidas del Par Vial de la Carrera 50. Fuente: Autores. 
Con el evento realizado en la carrera 50 como "Baila a la Calle", este proyecto tomó un valor cultural en la ciudad. En sus dos primeros años, 2017 y 2018, más de 100 mil personas han disfrutado de esta gran pista de baile consolidando 'Baila la Calle' como una gran apuesta para disfrutar el Carnaval de Barranquilla, con una gran oferta musical, gastronómica, artesanal y atractivas experiencias que van desde el viernes para arrancar el Carnaval, el sábado para parrandear y el domingo para rematar en el Par Vial de la carrera 50 uno de los eventos favoritos de los barranquilleros (Carnaval de Barranquilla, 2019).

Desde los años noventa, los cambios de estratificación y el incremento en el precio de los servicios han llevado al desalojo de muchos establecimientos industriales, talleres, comercio de insumos y herramientas, incrementando el uso de antiguas naves industriales como bodegas y produciendo la desocupación de predios que entran en proceso de deterioro, afectando la seguridad y la estética del sector (Vivas, 2013). Una de las respuestas para los diferentes rasgos de decadencia que presentaba el barrio fue a través del arte urbano propuesto en el par vial de carrera 50 que busca cambiar la percepción del barrio a través de la recuperación de la estética por medio de grafitis y colores que aluden a la tradición de Barranquilla. Artistas del festival de grafiti "Killart" han plasmado sus obras en los muros utilizando temáticas centradas en el Caribe. Este proyecto ha contado con el apoyo de la Alianza Francesa y la Secretaría de Cultura de la ciudad que desean que este espacio se constituya en el museo al aire libre más grande de la ciudad (Robles, 2017). Esto también ha despertado un sentido de pertenencia en el sector gracias que para algunos propietarios cuyas viviendas se encontraban en un estado deteriorado, hoy lucen diferentes gracias a esta política de renovación a través del arte urbano.

La obra del Par Vial de la Carrera 50 cuenta con más de $33.000 \mathrm{~m}^{2}$ de espacio público y cuatro carriles de vías hacia el centro histórico que ayudarán a desviar el tráfico. También cuenta con andenes de 3,80 $\mathrm{m}$ de ancho, ciclo-ruta de 1,20 $\mathrm{m}$ de ancho en ambos sentidos de la vía, 14 metros de vía en doble sentido, iluminación led en todo el espacio, redes subterráneas de telecomunicaciones, bancas y canecas, que dan un total de $5 \mathrm{~m}$ de ancho de espacio público en ambos costados.

\section{Conclusiones}

El Par vial de la carrera 50 constituye uno de los proyectos que han transformado la movilidad vehicular en la ciudad de Barranquilla, además, de su componente urbano de recuperación del espacio público y desarrollo cultural del sector. Para la ejecución del proyecto, se tuvo que demoler muchas viviendas con una connotación histórica importante en cuanto a la arquitectura y orígenes de Barrio Abajo; edificaciones que, aunque algunas estuvieran en un estado de estructura regular, mantenían las características constructivas desde que se erigieron: viviendas y edificaciones con puertas y ventanas de madera, tejas de cemento o en su defecto de arcilla, estilos arquitectónicos que iban desde el movimiento modernista hasta el art decó, elementos como detalles en las fachada 
elaboradas con cemento o yeso, etc. Edificaciones que hacían parte de la historia del barrio y de la misma ciudad de Barranquilla que, actualmente, solamente quedan fotografías de estas.

De cierto, el proyecto en la carrera 50 permitió la transformación urbana e incluso permitió el desarrollo cultural del sector. Con la nueva avenida, Barrio Abajo se consolidó aún más como un nodo cultural de la ciudad. Eventos del carnaval como Baila a la Calle y las famosas K-z en la carrera 50, reúnen miles de personas en la época de las carnestolendas. Una avenida de alto tráfico vehicular, donde el arte plasmado en grafitis en las paredes de las viviendas localizadas en la carrera 50, hacen del viaje por la carrera 50 una oportunidad para conocer la historia y cultura de la ciudad. Desde el norte de la ciudad hasta llevarnos al centro histórico, la carrera 50 es un antes y después en la dinámica sociocultural de la ciudad. Una carrera 50 antes del baile y una carrera 50 totalmente transformada.

El artículo fue estructurado abordando los temas de la 50 antes del baile, analizando la cultura, historia, arquitectura y primeras tradiciones del sector, hasta explicar la transformación de la carrera 50 que evoca una nueva visión de la cultura carnavalera, el arte y el resurgimiento de Barrio Abajo. De cierto, ya no existen las antiguas edificaciones de Barrio Abajo localizadas en la carrera 50, solamente quedan fotografías para el recuerdo que se compilan en el texto. Es importante resaltar que, la nueva carrera 50 o el Par vial de la carrera 50 permitió dar visibilidad a un sector que estuvo un tiempo en el olvido.

\section{REFERENCIAS}

Alcaldia de Barranquilla. (2012). POT Barranquilla 2012-2032. [Ley 388]. Barranquilla: Secretaria Distrital de Planeacion. Disponible en https://www.barranquilla.gov.co/ documento/perfiles-viales/?version=1.1

Carnaval de Barranquilla. (2019). 'Baila la Calle’ regresa con más música. [Online]. Disponible en http://www.carnavaldebarranquilla. org/baila-la-calle-regresa-con-mas-musica/

Carnaval de Barranquila. (2018). El Parque Cultural del Caribe y la Carrera 50, listos para ser la Esquina Cultural del Carnaval. [Online]. Disponible en http://www. carnavaldebarranquilla.org/el-parquecultural-del-caribe-y-la-carrera-50-listospara-ser-la-esquina-cultural-del-carnaval/

EDUBAR. (marzo 26, 2018). El par vial de la carrera 50 ya está totalmente habilitado. Edubar.com. Disponible en http://edubar. com.co/par-vial-la-carrera-50-ya-estatotalmente-habilitado/

Guerrero, A. (julio 16, 2016). Habilitan tramo del Par Vial de la carrera 50. El Heraldo. Disponible en https://www.elheraldo.co/ local/distrito-inaugura-primer-tramo-delpar-vial-de-la-carrera-50-272289

Pérez, J. M. (marzo 28, 2018). El tramo que va desde la calle Murillo hasta la calle 53 fue abierto oficialmente este lunes. La obra permitirá mejorar la movilidad en ese sector de la ciudad. El Heraldo. Disponible en https:// www.elheraldo.co/barranquilla/habilitanpar-vial-de-la-carrera-50-475082 
Polo, C. (diciembre 22, 2014). Barrio Abajo: entre la nostalgia y el par vial de la carrera 50. El Heraldo. Disponible en https://www.elheraldo.co/local/barrioabajo-entre-la-nostalgia-y-el-par-vial-dela-carrera-50-178292

República de Colombia. Ministerio de Cultura. (1 de diciembre de 2014). Plan Especial de Protección del Centro Histórico del Distrito Especial, Industrial y Portuario de Barranquilla. [Resolución No. 3779]. Disponible en https:// diario-oficial.vlex.com.co/vid/resolucionnumero-3779-2014-549019618
República de Colombia. Mintransporte. (6 de Agosto de 2002). Código Nacional de Tránsito. [Ley 769]. Diario Oficial: 44.893. Disponible en https://www.alcaldiabogota.gov.co/sisjur/ normas/Norma1.jsp?i $=5557$

Robles, L. (octubre 12, 2017). Par Vial de la carrera 50: Escape para el arte y el tráfico del centro de Barranquilla. Publimetro. Disponible en https://www.publimetro. co/co/barranquilla/2017/10/12/par-vial-lacarrera-50-escape-arte-trafico-del-centrobarranquilla.html

Vivas, J. M. (2013). Desarrollo urbano del Barrio Abajo: patrimonio olvidado. Barranquilla: Universidad del Norte. 